\title{
Teaching Evaluation of MOOCs Course
}

\author{
Xiao-fei XIAO \\ Higher Education Research Office \\ Jiangxi University of Traditional Chinese Medicine \\ Nanchang, Jiangxi, China \\ Lan LUO \\ School of Humanities \\ Jiangxi University of Traditional Chinese Medicine \\ Nanchang, Jiangxi, China
}

\author{
Tina-lin CHEN \\ Psychological Counseling Center \\ Jiangxi University of Traditional Chinese Medicine \\ Nanchang, Jiangxi, China \\ Guang CHEN* \\ School of Economy and Management \\ Jiangxi University of Traditional Chinese Medicine \\ Nanchang, Jiangxi, China
}

\begin{abstract}
In order to explore the teaching evaluation of MOOCS courses, this paper analyzes the content of MOOCs, including the origin and classification of MOOCs, and the characteristics and definitions of MOOCs, and also deeply analyzes the present situation and trend of MOOCs. Finally, the paper comprehensively interprets the teaching evaluation of MOOC courses based on the current situation of MOOCs courses in our university. The teaching evaluation of MOOCs mainly focuses on the following points: teaching philosophy, teaching objectives, teaching content, teaching method and teaching process. In order to clarify the teaching evaluation of MOOCS, we should first discuss the content of teaching evaluation. As far as we can see, teaching evaluation is the criterion for judging of the appropriateness of teaching goal, the effectiveness of teaching strategy and the degree of achievement of teaching goal (knowledge, ability, emotion).
\end{abstract}

\section{Keywords-Teaching evalution; MOOCs course}

\section{INTRODUCTION}

For a long time, I have always held the view that the understanding of anything is based on the concept, there is no way to recognize things without analyzing and defining the connotation of the concept. However, from the current point of view, no one has clearly defined the concept of MOOCs, in other words, the concept of MOOCs is constantly changing with the development of MOOCs. MOOCs is a transliteration word. We translate it into "love course". Many people use the meaning of their initials as the interpretation of its connotation.

MOOCs started in 2007 by David Wiley, a professor at Utah State University, it is based on the online open course named Intro to open Education which founded by wiki. This course has the characteristics of MOOCs, firstly, users around the world can share course resources, secondly, users can participate in curriculum innovation or curriculum development. 2008, Canadian scholars Dave Cormier and Bryan Alexander proposed. In September of the same year, Canadian scholars George Siemens and Stephen Downes use this concept to open the first real MOOCs course Connectivism and Connective Knowledge online Course. So why do we think this is the first MOOCS course? What is the difference between it and our traditional boutique courses, high-quality resource sharing courses, high-quality video open class and micro class?

The most essential difference between the traditional boutique courses, high-quality resource sharing courses, highquality video open class and MOOCs is that the change in teaching patterns resulting from the change of teaching philosophy. The design of excellent courses basically follows the idea of teachers, teaching materials and classroom as the center, and transplant the classroom to the network. MOOCs highlight the teaching philosophy of "student-centered", focusing on students' differences and Personalized to discover and accumulate their knowledge 1 .

\section{CHARACTERISTICS AND DEFINITION OF MOOCS}

We take a look at the characteristics of MOOCs courses, the past analysis of the MOOCs course' characteristics mostly stay on the representation of MOOCs.

According to the implication of MOOCs, domestic and foreign scholars believe that MOOCS has the following characteristics:

Firstly, Mass participation; the early stage is mainly reflected in some famous universities, famous teachers and famous courses. Foreign MOOCs platforms generally do not limit the number of registrations, students from all over the world are free to participate in their preferred courses. 2011, a course named introduction to artificial Intelligence taught by Stanford University's professor Schlum Thrunun was free[2]. It attracts more than 160 thousand people from more than 190 countries, these people have completed their registration and 20 thousand have completed the course. Now the three major platforms registered users are tens of millions.

Secondly, openness, the understanding of openness for many people is that learners can study for free and choose course by themselves. In fact, my understanding of openness refers to the spirit of openness, democracy and academic freedom. This involves not only learners, but also teachers. 
Thirdly, Interactivity or generative. Because the students' knowledge background, cognitive level, region, age, and gender vary greatly, the content of the course changes with the students' discussion.

According to the characteristics of MOOCs video production, it is generally divided according to knowledge, so the time of video control is generally 5-10 minutes, so that learners can make use of the fragmentation time to study.

In terms of MOOCs learning methods, registration is generally required. Lecturers push video at a specific time, they design and assess the scoring process. After learning all the knowledge points can obtain the credit certificate. It should be said that the study of MOOCs pays special attention to formative assessment, which is also closely related to the interactivity mentioned above.

\section{CURRENT SITUATION AND TREND OF MOOCS}

\section{A. Current situation of MOOCS}

Education authorities are being pressured to respond. MOOCS has forced universities and the Ministry of Education to react in a bottom-up way. In 2012, the New York times wrote that MOOCs were a "storm" of bottom-up reform, pushing the last wall in the 21st century. Most of the world's top universities have joined the MOOCS camp in various ways or provided MOOCS services, both for profit and non-profit. Udacity Coursera edX abroad, XuetangX, east China normal university's centre for class along with a variety of for-profit companies, as we know, MOOCs, super star, rain course, wisdom tree, eastern and western union and so on. In 2012, it was called the first year of MOOCS. In 2013, it was called the first year of China's MOOCS. In 2014, the number of MOOCS users in China was only 1.5 million. In 2015, the number of users reached 5.75 million, up 283\% year-on-year. In 2015, the ministry of education issued the "opinions on strengthening the application and management of online open courses for colleges and universities", it proposed to build an online open course system and course platform with Chinese characteristics. The policy is "university subject, government support, social participation". Based on the independent construction, we should pay attention to application sharing and strengthen the standard management. This has strongly promoted the construction and application of online open courses in China. It has more than 700 schools, 5,200 courses and more than 38 million students. At present, the construction and application of MOOCs in China has exploded, and many high-level universities have begun to take courses on the international famous courses. Relevant universities and institutions have independently built more than 10 domestic MOOCs, and 55 million students and social learners are selected for courses. The number of MOOCs in China is the highest in the world.

Helping big data teaching become a reality. The integration of information technology and teaching promotes the advent of big data teaching era. Although I am not willing to accept this reality, I do not believe that computer technology can change the nature of teaching. But with the development of MOOCs, the integration of big data analysis, information technology and teaching will become an irreversible trend. We find that more and more relevant teaching applications exist, video shooting is becoming more and more "film and television." As a result of mass online open courses, mass learning data make our teaching and learning become an inevitable trend under big data.

Diversification of MOOCS applications. The mode of operation of MOOCS and the fields both are become more and more diversified. As mentioned earlier, the MOOCS platform has a profit-making nature and a non-profit nature [3]. But its diversification emphasizes that MOOCs' business model already involves a variety of business models, such as data mining, add-on services, credit charges, advertising fees, and selling classes to institutions. And MOOCS has been expanding from higher education to basic education in the field of application.

MOOCs are making higher demands on the teaching subjects. MOOCS itself still faces many challenges that need to be actively improved. From the perspective of learners and teachers, we find that: First of all, there are a large number of people register MOOCs, but the study is not persistent and the dropout rate is high; Secondly, MOOCS students are complicated, and different cultural backgrounds and languages influence the effectiveness of communication and learning. Thirdly, the generative curriculum content makes the teaching objectives difficult to control, and the requirements of teachers are greatly improved.

\section{B. The trend of MOOCS development (influence)}

To make the "student-centered" teaching model a possibility. The author once pointed out that the "studentcentered" teaching model is almost impossible in the traditional classroom. The reason is that "student-centered" is not only a kind of innovation of educational ideas, but also needs a huge amount of high-quality educational resources as a guarantee. It needs strong technical support to protect it. With the development of MOOCS, we can see that the student-centered educational concept, such as autonomous learning and individualized learning, is a possibility. The development of MOOCS will promote the emergence of a new teaching and learning model.

To promote the transformation of the functions of colleges and universities. Since the emergence of medieval universities, there has been almost no change in the form and structure of this ancient and vital academic organization. The functions are constantly renewed, from talent training to scientific research to social services. The attack of MOOCS storm may cause great changes in the internal and external management functions of universities, so that the stronger the stronger, the weaker the weak.

The subject knowledge system should be reconstructed, the professional boundaries should be broken. Because of the generative characteristics of MOOCS, it will break the classification of original knowledge and the division of specialty, and require the two subjects of teaching and learning have a higher level of understanding and the ability of interdisciplinary knowledge. This is bound to the original discipline knowledge system and professional division. 


\section{THE TEACHING EVALUATION OF MOOCS COURSE}

\section{A. The present situation of MOOCs course in our school}

In 2013, we took the opportunity of the central financial project, "Teaching team building based on the training of teaching standard soldiers", to promote the construction of curriculum and teaching team. The course construction is constructed according to the main courses, core courses, basic courses and ideas of public courses. Dean of teaching team in accordance with the teaching workshops "tube, built" as the main task, teaching masters workshop "leading" as the main task, teachers' workshop "demonstration" as the main task, address in the actual teaching problems in the process of school

We believe that the construction of university-level MOOCs will help at least in two ways. Firstly, it is helpful for teachers to systemize the knowledge system of the courses which they taught. Secondly, it is helpful for teachers to carry out more teaching activities and enhance teachers' discussion teaching. Looking back on it, it has unexpected harvest. Since 2013, we have declared two national quality resource sharing courses, one excellent video open class, and nearly 30 provincial quality resource sharing courses, all of which are related to the construction of MOOCs at that time [4]. Since last year, the provincial-level quality online open course evaluation is more focused on the course application and Number of electors. We have "Nutrition and Diet" 8 courses recommended to be run on the East-West Alliance shared platform, where individual teachers not only have material returns, but also have increased influence.

\section{B. Teaching evaluation of MOOCS courses}

In order to clarify the teaching evaluation of MOOCS, we should first discuss what is teaching evaluation. As far as I understand, teaching evaluation is a judgement of the appropriateness of teaching goal, the effectiveness of teaching strategy and the degree of achievement of teaching goal (knowledge, ability, emotion). According to its function in teaching activities, teaching evaluation can be divided into orientation evaluation(Before teaching activities, students should be informed of their preparation, knowledge and skills required, students' interests and habits, etc., to select teaching methods), formative evaluation(Feedback the success and failure information in the teaching process, reinforce the successful place, and show what needs to be improved), diagnostic evaluation(Review students' learning errors and investigate the underlying causes of repeated errors.) and summative evaluation(Judge the degree of reaching the teaching goal). According to different subjects, teaching evaluation can be divided into individual self evaluation, group evaluation, teacher evaluation (supervision evaluation).

\section{CONCLUSION}

The evaluation of our experts is mainly about the teacher's evaluation of the classroom teaching effect. I think the teaching evaluation of MOOCs is mainly concerned with the following: teaching philosophy, teaching objectives, teaching contents, teaching methods, teaching process

\section{REFERENCES}

[1] Y Li , B Zhao, J Zhou. Design and development of adaptive minority ethnic culture MOOCSs platform. International conference on educational innovation through technology [J], 2017:6-9.

[2] S Warburton, Y Mor. A set of patterns for the structured design of MOOCSs. Open learning : the journal of open,distance[J], 2015 , 30(3) :206-220.

[3] M Liu, Z Zhu. A study of pedagogical patterns for designing MOOCSs China educational technology [J],2014.

[4] P Balaouras, M Gatzonis, K Tsimpanis. Towards an online video platform for MOOCSS. Multimedia tools \&application [J], 2017(4):1-27. 